\title{
MODELLING OF ELECTRIC DRIVE FOR EXCAVATOR PUMP
}

\author{
J. Nevrlý ${ }^{*}$ Z. Němec ${ }^{* *}$, I. Pazdera ${ }^{* * *}$, M. Nožka ${ }^{\dagger}$
}

\begin{abstract}
The present article substantiates and describes some characteristic features used in modelling of an excavator electric drive. The article introduces basic model schemes of the drive system, the simulation model of the Engineering electric motor system, the pump driven by the electric motor, examples of simulation results time courses of model quantities received either by means of Matlab/Simulink or a set of differential equations.
\end{abstract}

Keywords: modelling, electric drive, pump, excavator

\section{Introduction}

The electric drive of excavator powered exclusively by means of electric accumulators as a single source of energy is a crucial innovation in contradiction to the traditional drive using an internal combustion engine. In our particular case equipped with such equipment, it is an innovation of the mini-excavator E19 up to $2 \mathrm{t}$ produced by the company Bobcat Doosan. The innovated machine can work in closed space, premises enclosed of hospitals, protected areas, etc. because surroundings are not burdened with exhaust gases and noise.

\section{General model of electric drive of excavator pump}

Mathematical modelling of individual subsystems and also of the entire excavator enables to improve properties of designed construction including the significant subsystem of electric drive of pump. Connecting the pump into the system of the excavator is illustrated in Fig. 1.

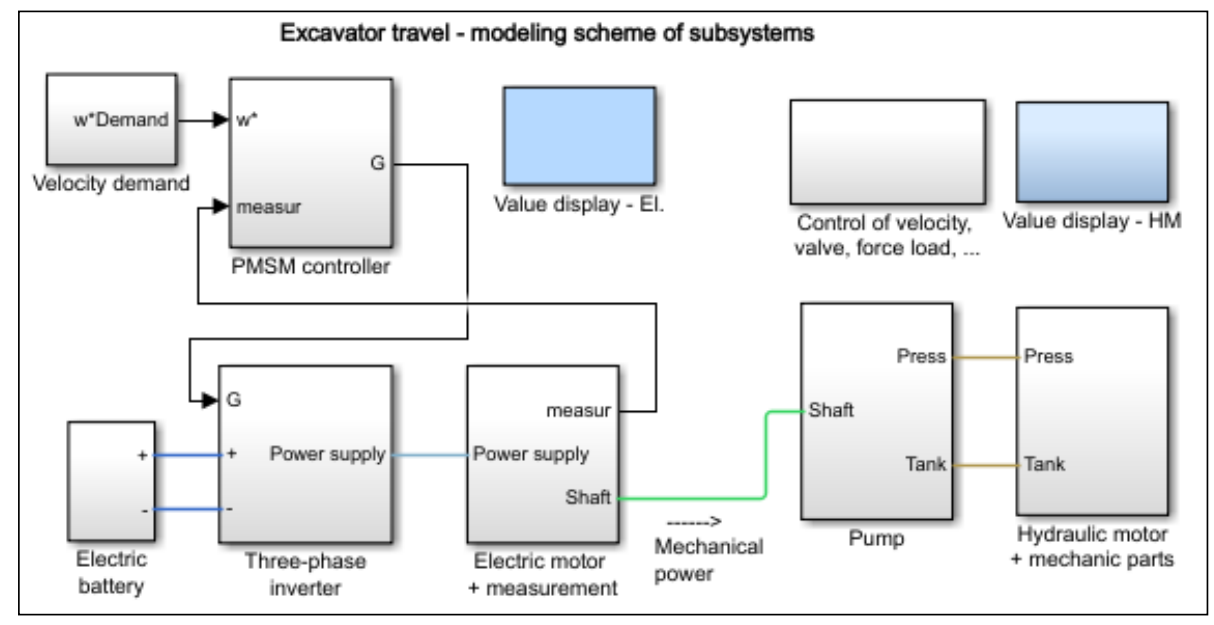

Fig. 1: The general model of electric drive of excavator pump ${ }^{\cdots . .}$

* Prof. RNDr. Ing. CSc., 6166900 Brno, Technická 2, CZ, Faculty of Mechanical Engineering, BUT, nevrly@fme.vutbr.cz

** Doc. Ing. CSc., 61669 Brno, Technická 2, CZ, Faculty of Mechanical Engineering, BUT, nemec@ffme.vutbr.cz

*** Ing. Ph.D.., 61669 Brno, Technická12, CZ, Faculty of Electrical Engineering and Communication Technology, BUT, pazdera@feec.vutbr.cz

† Bc., 61669 Brno, Technická 2, CZ, Faculty of Mechanical Engineering, BUT, nozkamichal@gmail.com 


\section{Subsystem of electric motor}

For the drive, electric synchronous motor with rotor equipped with permanent magnets (PMSM) was used.

The model of the subsystem of driving electric motor including measurements of mechanical quantities can be seen in Fig. 2. The electric motor was modelled by the block Permanent Magnet Synchronous Motor taken from Simulink library. The model shows the influence of inertia moment of the electric motor and built-in sensors of torque of the electric motor, and frequency of motor speed.

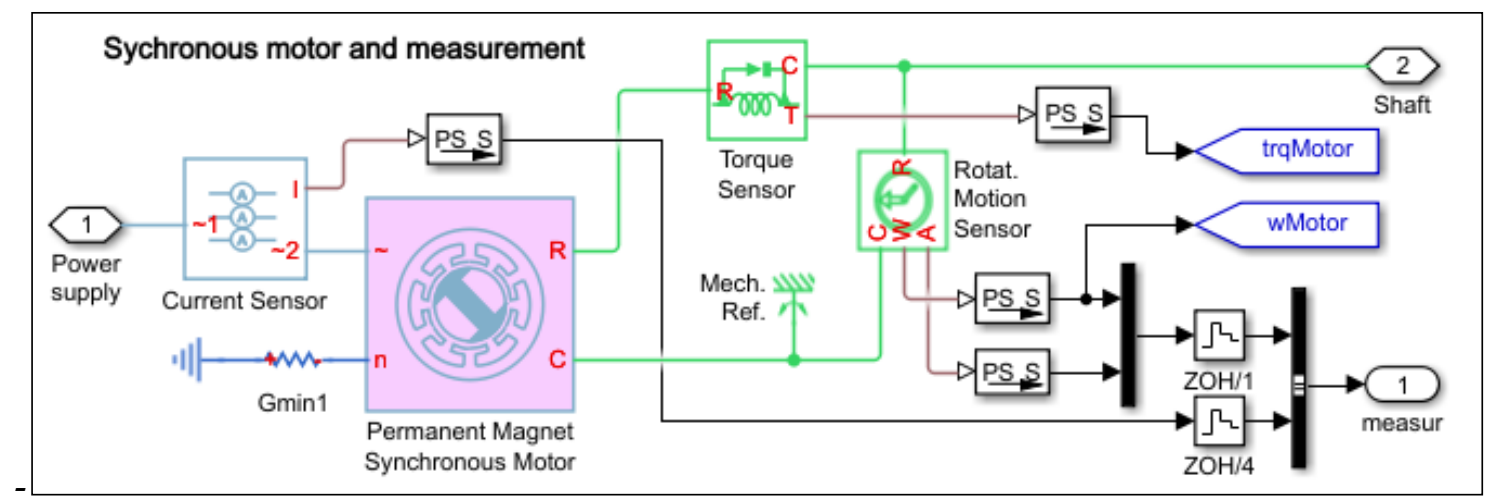

Fig. 2: Model of driving electric motor

\section{The subsystem of pump}

In the excavator, the pump is the only source of pressurized oil for hydraulic motors of arm, for travel and rotation. In the model, the pump is driven by an ideal source of angular velocity controlled by signals from the block Signal Builder. Sensors of oil pressure, oil flow, torque and pump speed are deployed in suitable places in the model. More information concerning chaps. 3 and 4 can be seen in (Němec, 2016).

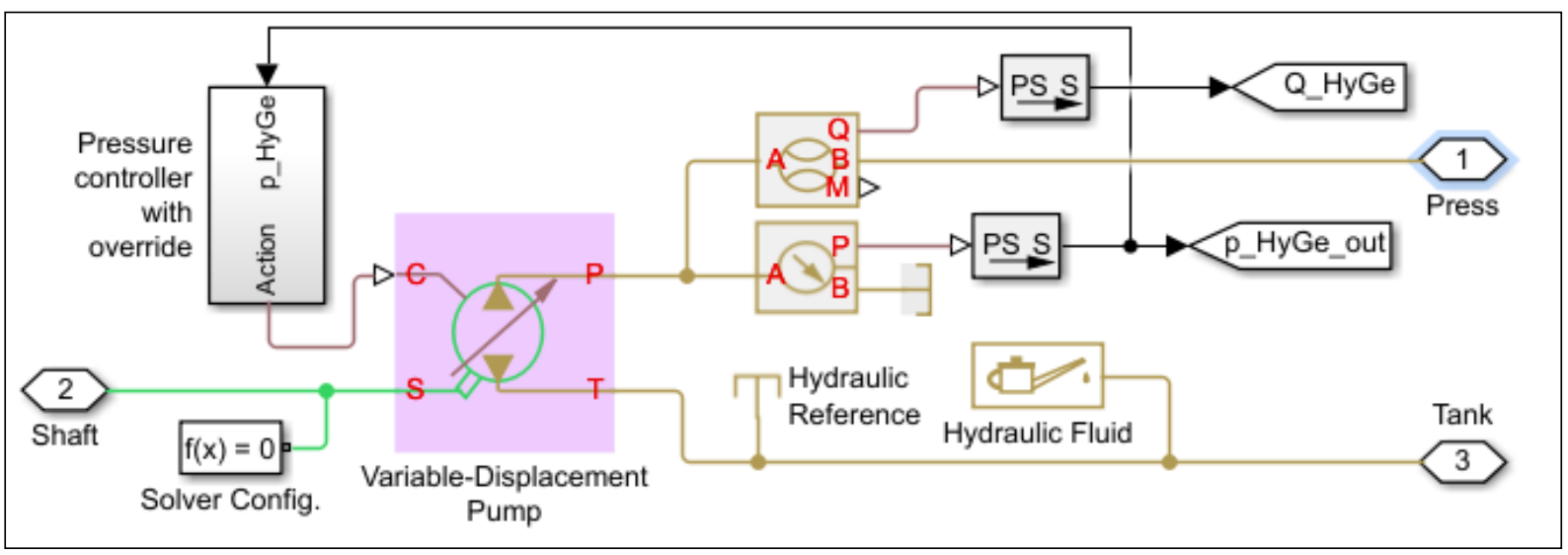

Fig. 3: Model of pump and its connection for verification of correct function

\section{Simulation of electric drive of excavator}

An example of simulation of electric drive in the mode of speed control and with step changes in torque is given in Fig. 4.

\section{Measurement of pump efficiency}

Pump efficiency is one of the variables which, in significant extent, influences the properties of excavator electro-hydraulic drive. This variable depends on multiple factors - pressure, flow, speed frequency, oil temperature, etc. Owing to the fact that the pump manufacturer lists in the respective catalogue only one value of this efficiency, it was necessary to deal with at least the reference measurement of this variable. 

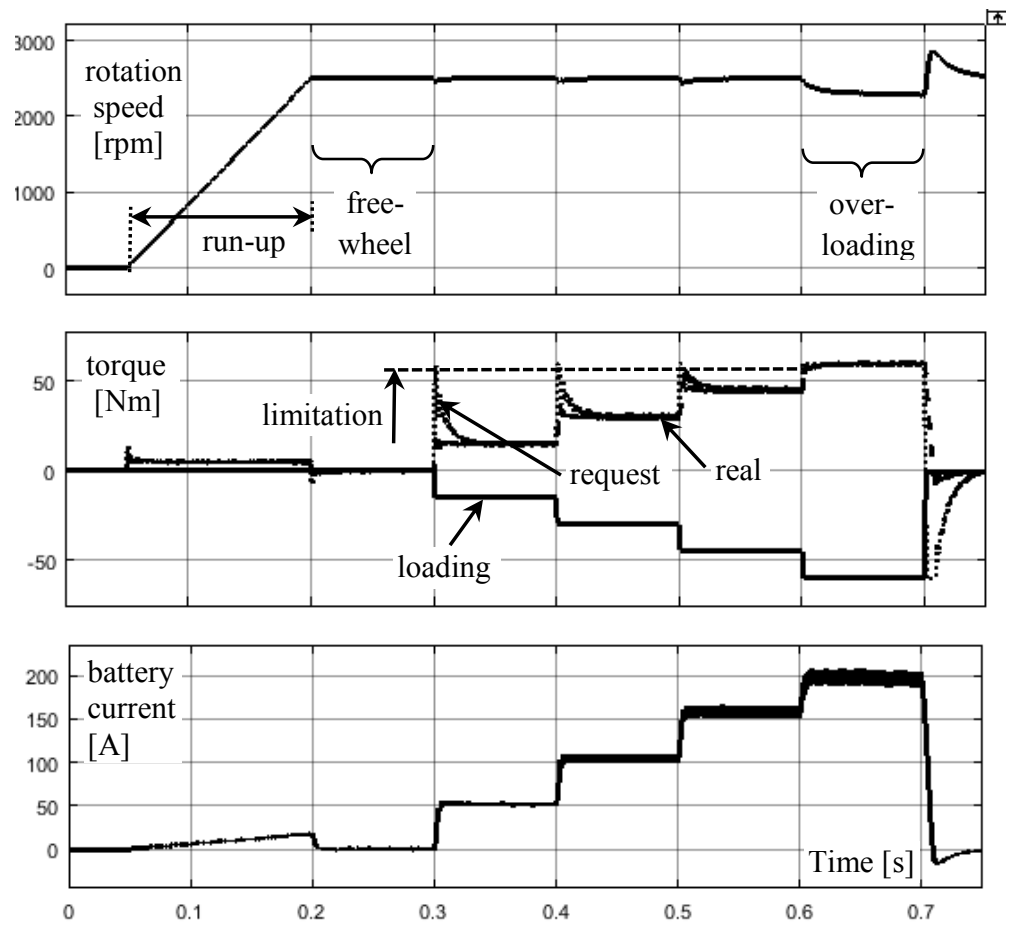

Fig. 4: Results of drive simulation

For mathematical modelling, we can use a simple method to estimate the efficiency of pump and motor. Calculation is based on the comparison of power draw from battery $\left(\mathrm{P}_{\mathrm{b}}\right)$, mechanical power produced by motor $\left(\mathrm{P}_{\mathrm{m}}\right)$ and hydraulic pump power $\left(\mathrm{P}_{\mathrm{h}}\right)$. Efficiency of synchronous belt drive is considered as constant $\left(\eta_{\mathrm{b}}=98 \%\right)$. To ensure that the oil temperature will not change during the test, it is necessary to use, especially at high hydraulic loads, a large oil reservoir and an oil cooler. This type of efficiency measurement is not in compliance with standards (ISO 4409) but it allows us to estimate the model parameters promptly and with sufficient accuracy.
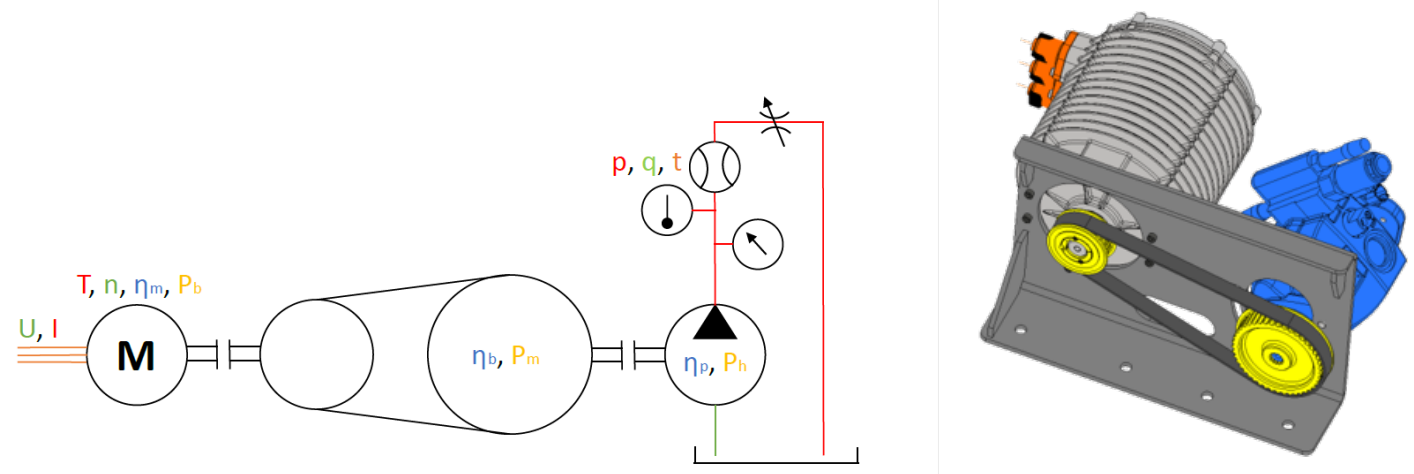

Fig. 5: The diagram of simplified pump efficiency measurement

\section{Modelling of electric drive of excavator pump by means of differential equations}

A synchronous electric motor with smooth rotor was considered because its arrangement ensures equality of stator inductivity in individual coordinate axes $d, q$. Three-phase stator winding was substituted in the two-phase model with inductivity $L_{d}$ in longitudinal axis and $L_{q}$ in transverse axis. Only for reference (a more detailed description concerning equations and further diagrams see in (Vorel et al., 2016)), the model of the above - mentioned motor is given by the following equations.

$$
\begin{aligned}
& u_{d}=R_{s} i_{d}+L_{d} \frac{d i_{d}}{d t}-\omega L_{q} i_{q} \\
& u_{q}=R_{s} i_{q}+L_{q} \frac{d i_{q}}{d t}+\omega L_{d} i_{d}+\omega \Psi_{f},
\end{aligned}
$$


where $\Psi_{f}$ represents a coupled actuating current of permanent magnets, $\mathrm{R}_{\mathrm{s}}$ is resistance of stator winding, and $\omega$ is electric angular frequency. Equations (1) and (2) represent the electric part of the electric motor. For the moment of the electric motor, it holds:

$$
M_{m}=\frac{3}{2} p_{p}\left[\Psi_{f} i_{q}+\left(L_{d}-L_{q}\right) i_{d} i_{q}\right]
$$

where $p_{p}$ is the number of pole pairs. This equation is true when precise alignment of the $d, q$ coordinate system with the permanent magnets flux on the rotor is ensured. The overall motor model is further complemented by a motion equation in rotating variables:

$$
J \frac{d \omega_{\text {mech }}}{d t}=\frac{J}{p_{p}} \frac{d \omega}{d t}=M_{m}(t)-M_{z}(t)
$$

where $J$ is moment of inertia of the rotor, $M_{\mathrm{z}}$ is moment of load, and $M_{\mathrm{m}}$ is internal moment of the motor.

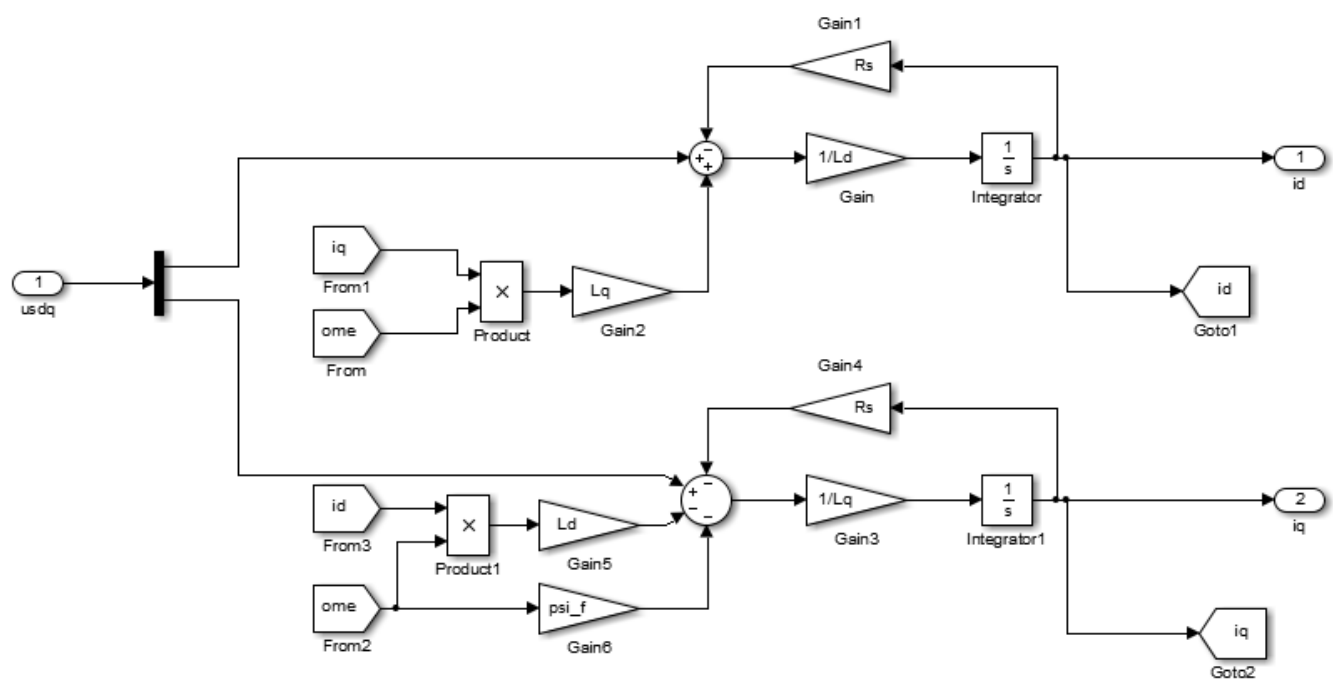

Fig. 6: Model of voltage differential equations (1) and (2) of the electric motor

\section{Conclusion}

Modelling of electric drive of mini-excavator pump brought interesting and necessary findings concerning a newly proposed way of the device drive. We aim at creating an energy-sufficient system including electronic and hydraulic equipment with better dynamic properties in comparison with contemporary drives using internal combustion engines. It is modelling that enables to achieve a quality solution hardly attainable using other ways.

\section{Acknowledgement}

The research leading to these results has received funding from the MEYS under the National Sustainability Programme I (Project LO1202) and from the MIT under TRIO programme (Project FV10411).

\section{References}

Němec, Z. (2016) Models of subsystems of functional pattern of mini excavator up 2 t, (In Czech: Matematické modely subsystémů funkčního vzoru mini-exkavátoru). Brno, BUT, Faculty of Mechnical Engineering,. [Partial report of the project FV 10411].

Vorel, P., Prochazka, P., Pazdera, I. and Halek, V. (2016) Partial research report of the project FV 10411, stage E01.3. (In Czech: Dílčí výzkumná zpráva k projektu FV10411 Etapa E01.3). Brno: BUT, Faculty of Electrical Engineering and Communication Technology. 